\title{
PUBLIC-PRIVATE PARTNERSHIP AS A MECHANISM FOR FINANCING INFRASTRUCTURE MODERNIZATION
}

\author{
Olha Kravchenko'
}

\begin{abstract}
The article is devoted to the study of the possibilities of attracting private business for financing stateowned infrastructural facilities. The purpose of the paper is to study the practice of attracting private business for the modernization of infrastructure, including railway and the development of an approach to the formation of a variety of infrastructural objects transferred to the public-private partnership, based on an assessment of the possible reduction of their potential. Methodology. The study is based on an empirical analysis of data on the practice of financing infrastructure modernization, as well as a SWOT analysis of the prospects for the development of European railways. Results of the research showed that the public-private partnership has significant advantages over the budgetary one due to not only reducing the financial burden on the state budget but also increasing the efficiency of using state-owned facilities. In the field of railway transport, the volume of public-private partnership and the number of projects being implemented is insignificant due to significant state interference in its activities. SWOT analysis showed that railways have significant development potential, and its further increase will be achieved not through expansion of the network, but its modernization and innovative development. The dangers of the development of railways are associated with possible ineffective state policy in the field of railway transport. However, the complete transfer of the rail infrastructure to private business is not expedient since it is of strategic importance. The determination of the list of facilities for transfer to public-private partnership should be based on an analysis of the degree of their interest in private business, the need for their modernization and the possibilities for its financing. These objects are sections of the railway network included in transport corridors, as well as providing access to seaports. At the same time, the criterion of the first priority of the transfer of objects for the public-private partnership should be based on an assessment of the change in their production and economic potential when postponing modernization. Value/originality. The implementation of the proposed approach to the selection of infrastructure facilities for public-private partnership will allow not only carrying out technical and technological renovation of the railway infrastructure, preserving the integrity of the strategic transport network, but also minimizing possible economic and social losses due to underfunding of its innovative development.
\end{abstract}

Key words: infrastructure, modernization, financing, public-private partnership, rail transport.

JEL Classification: G32, H54, R42, L92

\section{Introduction}

In the second half of the XX century, the process of cardinal changes in all spheres of the social and economic life of both developed and developing countries began. This was the result of the formation of a new paradigm of economic development, the objective consequence of which was the change in key determinants of the management of the national economies. The structural changes that have taken place also touched on spheres that were traditionally considered to be facilities of the direct state administration. The integration processes taking place on the Eurasian continent necessitate the formation of a developed infrastructure that must be not only innovative but also interconnected, i.e. form a single network and be interoperable to ensure the

Corresponding author:

${ }^{1}$ State University of Infrastructure and Technology, Ukraine.

E-mail: kravch.olha@gmail.com free movement of resources, goods, and services both within the state and with foreign partners. According to the Organization for Economic Cooperation and Development, improving the quality of infrastructure also stimulates productivity growth (Cova, Pagano, Notarpietro, Pisani, 2017). This necessitates a significant investment in infrastructure, the development of which should be spent up to $4.1 \%$ of GDP (McKinsey Global Institute, 2013). The experts of the McKinsey Global Institute note that in order to ensure the predicted growth of world GDP, the investment in infrastructure should reach 57 trillion USD up to 2030. It is obvious that it is virtually impossible for governments of even developed countries to finance the necessary capital investments at the expense of the state budget 
(the infrastructure of the EU countries is financed at $84 \%$, other developed countries $-91 \%$ of the required level).

At the same time, such investments should be considered as an indispensable condition for the development of the national and global economy, the failure of which leads to negative consequences for both the state and private business. The experts note that in the conditions of the budget deficits, the state will stimulate the emergence of new interesting investment opportunities (Ernest \& Young (CIS), 2014). Thus, the problem of the formation of sufficient financial resources for the development of infrastructure is relevant for theoretical and applied research. To solve this problem, the practice of attracting private capital for modernizing the infrastructure by the example of the railway was explored, and an approach was proposed to the formation of a number of the infrastructural facilities transferred for modernization and further exploitation to private structures, based on an assessment of the possible reduction of their potential in the event that capital investments in them are postponed due to the lack of available financial resources.

\section{Models for financing infrastructure development}

As already noted, the state funds for the development of infrastructure are not enough now. This determines the need to attract the private business to finance both the modernization of existing facilities and the creation of new ones. One of the most promising forms of such cooperation between the state and private business is now recognized as Public-Private Partnership (PPP). According to the World Bank, PPP is used in more than 134 countries; $15-20 \%$ of all investments in infrastructure are financed at their expense (World Bank Group, 2015a).

Modern PPP theory develops on the basis of liberalconservative doctrines, which are the basis of the institutional economic theory. In modern terms, PPP is viewed as an institutional and organizational alliance between the state and business in order to implement the national and international, large-scale and local, but always socially significant projects in a wide range of activities (Varnavsky, 2005). At the same time, there is a departure from the traditional position according to which PPP is possible only in industries, in which the transfer of state property to private ownership is prohibited. The adaptive approach, which predetermines the possibility of PPP in any spheres, where such interaction will be effective and mutually beneficial, is becoming more widespread.

PPP is recognized as the most progressive company of the partnership between the state and private business. This is due to the fact that such a partnership gives significant advantages over the budgetary one due to: (1) reducing the financial burden on the state budget, increasing the efficiency of using state-owned facilities, improving the quality of service; (2) of a long-term nature with clearly defined time frames, which allows not only short-term and medium-term planning but also strategic planning. In addition, the widespread introduction of concessions makes it possible to expand the opportunities for attracting the private investments in industries where privatization is impossible, to modernize them without losing control over facilities of strategic importance for the state. The consequence is an increase in the frequency of use of PPP mechanisms in developing countries (Colverson, Perera, 2011).

In developed countries, there is a considerable positive experience in creating such temporary alliances for the implementation of the specific projects. The World Bankidentifies three main types of PPP: ROT (Rehabilitate-Operate-Transfer), RLT (RehabilitateLease-Transfer), BROT (Build-Rehabilitate-OperateTransfer) (World Bank Group, 2015a). These types of PPP oblige concessionaires to perform certain works to modernize (improve) the property received (transferred) under the contract, while the cost of the works performed is not refundable.

In the scientific literature, 5 main types of concession contracts are considered (Hanaoka, Perez Palapus, 2012; Kilvington, 1996; etc.).

BOT "Build-Operate-Transfer" (or DBOT "DesignBuild-Operate-Transfer") is a classical concession model that underpins PPP legislation in many European countries. The conclusion of such a contract assumes that the concessionaire performs the entire complex of works on the construction (reconstruction) of the facility, exploits it, and receives from it income within a certain (fixed) period, after which the facility is transferred to a public partner (state, authorized state bodies, etc.);

BTO "Build-Transfer-Operate" involves financing the entire complex of works on the construction (reconstruction) of the facility by the private investors and transferring it to the ownership of a public partner immediately after the construction is completed; concessionaires receive this facility for the further exploitation and income generation.

BOO "Built-Own-Operate" (or DBOO "DesignBuilt-Own-Operate"). Private investors carry out the construction (reconstruction) of the facility, and then acquire ownership of it, on the basis of which it is used for a period agreed with the public partner.

BOOT "Built-Own-Operate-Transfer" (or DBOOT "Design-Built-Own-Operate-Transfer"). Private investors carry out the construction (reconstruction) of the property, acquire ownership of it, and operate for a certain period of time, after which the facility is transferred to the ownership of a public partner.

BBO "Buy-Build-Operate" (or LDO "LeaseDevelop-Operate", WAA "Wrap-Around-Addition"). The peculiarity of these concession models is that they 
are a kind of transfer of already existing assets to the ownership of the private partners who must modernize these facilities without taking any obligations on the terms of its transfer to a public partner.

\section{Railways as a facility of public-private partnerships}

When formulating PPP conditions and, as a consequence, the choice of the concession model, there is always a problem of harmonizing the social and economic efficiency of its implementation, which is exacerbated by the analysis of the infrastructure facilities of strategic importance. This is also true for rail transport, which is now returning its significance as a locomotive of development' not only for developing economies but also for developed ones, which also has a great social significance. At the same time, the technological features of railways determine their monopoly position not only as one of the most accessible modes of transport but also the main carrier of a certain range of goods, primarily large volumes of bulk materials from the centres of their production (mining and agricultural products) to the place of their further processing. Effective rail transport can become an important catalyst for economic growth and development, stimulate trade, link production sites to the regional and international markets, promote national and cross-border integration of regions and facilitate access to the labour market, education and health services. In addition, rail transportation is more energy efficient than automobile or aviation, which is especially important in the face of rising energy shortages.

It is expected that $€ 1.8$ billion will be directed to the development of the strategic sections of the railway network that provide the 'highest EU added-value and impact' (European Commission, 2017). However, the centralized financing of the infrastructure both at the EU level and the governments of individual states is not effective enough, because (1) the main criterion for selecting projects is not the appropriateness of their implementation but the necessary amount of financing that is the main is not the strategic aspect of the railway network development, short-term effect; (2) financing of short-term projects aimed at maintaining the infrastructure in working order, rather than its innovative development, is a priority. In addition, the consequence of the direct subsidization of rail transport is in a sense dependent behaviour that negatively affects the efficiency of its operation.

At the same time, World Bank experts note that attracting private capital, including through PPP on railways, will improve the efficiency of railways through the introduction of modern and clean technologies (World Bank Group, 2017). Effective joint use of the railway infrastructure, modernized as a result of the implementation of the RRP, will help to increase not only the incomes of the state and private investors but also the attractiveness of the capital investment in the development of the railways.

Now, in terms of the volume of PPP and the number of projects being implemented, rail transport is at the 3rd (penultimate) position among other modes of transport (Figure 1). In 2015, according to the World Bank, 5.8 billion USD was raised for the development of railways through the PPP mechanism (World Bank Group 2015b). Despite the strengthening of the position of railway transport, its attractiveness for private business has declined. So, during the period of 2010-2014, annually, investments in its development with the participation of private business averaged to 8.6 billion USD, that is, in 2015 they were less than the average annual level by $33 \%$. At the same time, the total volume of such investments in the development of transport infrastructure increased by $53 \%$ compared to the average level for the previous five years. Of the seven projects concluded on the basis of PPP, only one is connected with the main railways and the rest - with the development of the subway.

This situation is the consequence of (1) the great social significance of rail transport, its role in ensuring the national security of the state and, as a result, significant state intervention in production and economic activity, and (2) the fact that the maximization of profits from its use cannot be the basic principle of development (M. Sussman, 2013). This determines the need to tighten the terms of the concession agreements related to the development of the railway infrastructure.

At the same time, SWOT analysis, conducted for the European railways (Table 1), demonstrates the high potential of rail transportation. At the same time, the potential will increase substantially in the conditions of the 'industrial renaissance', when the need for regular and stable transportation of large volumes of goods to medium and long distances increases. The increase in capacity (network capacity and transport capacity) will be achieved through the non-expansion of the network (developed European countries already have welldeveloped rail networks), and its modernization and innovative development.

As can be seen from Table 1, the dangers of the development of rail transport are mainly related, on the one hand, to the possible irrational state policy in the field of railway transport, and on the other hand, to the ineffectiveness of the market mechanism. The experts of the International Bank for Reconstruction and Development indicate that the success of the implementation of PPP projects is largely determined by government support, developed legal framework, a correct assessment of the ratio of benefits and costs, as well as the distribution of risks (IBRD, 2012). Thus, these problems can be minimized by implementing a balanced state strategy to support the innovative development of the transport infrastructure. 


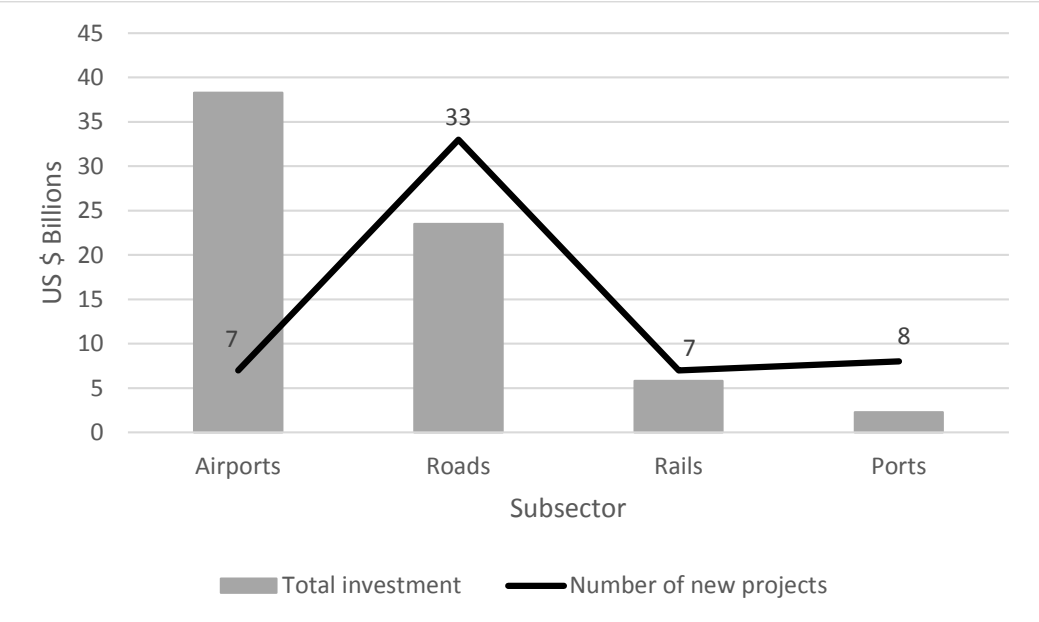

Figure 1. Investments in transport by subsectors

Source: built by the author based on World Bank Group, $2015 b$

Table 1

SWOT Matrix for Railways

\begin{tabular}{|c|c|}
\hline Strengths & Weaknesses \\
\hline $\begin{array}{l}\text { 1. A fairly stable customer base. } \\
\text { 2. The possibility of year-round transportation; independence from weather conditions. } \\
\text { 3. The possibility of carrying out mass transportations for long and medium distances. } \\
\text { 4. Large load capacity of rolling stock. } \\
\text { 5. The possibility of transportation in specialized cars. } \\
\text { 6. A fairly stable customer base. } \\
\text { 7. Traction unit has high reliability and durability. } \\
\text { 8. High traffic safety. } \\
\text { 9. High environmental friendliness of transport. }\end{array}$ & $\begin{array}{l}\text { 1. Binding to the network of railways, the construction } \\
\text { of which is very expensive. } \\
\text { 2. The high cost of initial-final operations (stations and } \\
\text { devices in places of loading and unloading). } \\
\text { 3. The high cost of maintaining the infrastructure. } \\
\text { 4. Long payback periods for investments in } \\
\text { infrastructure and rolling stock. } \\
\text { 5. The necessity of subsidizing passenger transportation. } \\
\text { 6. High level of state intervention in financial and } \\
\text { production activities. }\end{array}$ \\
\hline Opportunities & \\
\hline $\begin{array}{l}\text { 1. Creation of a single transcontinental network Europe-Asia. } \\
\text { 2. Internationalization of rail transport. } \\
\text { 3. Realization of the policy of 'industrial renaissance' in EU countries; high rates } \\
\text { of development of the Asian economies. } \\
\text { 4. Possibilities for increasing the volume of transport. } \\
\text { 5. Development of multimodal and intermodal transport. } \\
\text { 6. Growth in demand for high-speed passenger transportation. } \\
\text { 7. The possibility of an innovative leap in railway technology over the next 3-5 years. }\end{array}$ & $\begin{array}{l}\text { 1. The difficulties of ensuring the full interoperability of } \\
\text { railway networks of different countries. } \\
\text { 2. Imbalance in supply and demand for services in the } \\
\text { industry. } \\
\text { 3. Reducing the competitiveness of rail transport. } \\
\text { 4. Tougher state regulation of rail transport. } \\
\text { 5. Unreasonable pricing policy of railway companies. }\end{array}$ \\
\hline
\end{tabular}

Source: developed by the author using data from (Drexler T., 2012; European Commission, 2008; PwC, 2015; etc.)

Since the railway infrastructure is of strategic importance, its full transfer to private business is not expedient. This can be explained by the fact that (a) the state may for some time lose control over the strategic facility; (b) private business may violate the terms of the contract, which will result in not becoming an innovative infrastructure development, but its deterioration. Therefore, there is a set of problems associated with the transfer of facilities (sections of the railway network) for PPP. Let's consider some of them.

Problem 1. Define the list of PPP facilities. Such facilities must satisfy the following conditions:

(1) the facility should be of interest to private business, that is, the expected benefits of operating the facility should exceed the costs of its modernization, that is:

$$
\sum_{t=t_{b}}^{T} \frac{\boldsymbol{P}_{k}(\boldsymbol{t})}{(1+\boldsymbol{d})^{t}} \geq \sum_{t=0}^{t_{f}} \frac{\boldsymbol{K I}(\boldsymbol{t})}{(1+\boldsymbol{d})^{t}},
$$

where $t(t=\overline{0, T})$ - years of the implementation of the concession agreement; $t_{f}$ - year of end of financing of modernization of the concession facility; $t_{b}$ - the year from which the concessionaires will profit from the operation of the facility; $P_{k}(t)$ - profit planned for the year $t$; $K I(t)$ - capital investments provided for by the concession agreement; $d$ - the price of the capital;

(2) there is an urgent need to modernize a facility or section of the railway network, given that there is an acute shortage of financial resources for the implementation of such a project, that is:

$F R_{n} \geq F P$, 
where $F R_{n}$ - the amount of financial resources required to upgrade an infrastructure facility or a network section; FP - financial capabilities of the state budget.

The analysis showed that the sites that meet these conditions are sections of the railway network included in transport corridors, as well as providing access to seaports. In this case, the following will be provided:

firstly, the necessary balance between the economic interests of investors (concessionaires) and the state since these sections of the network are the most in demand in the process of transport, especially multimodal and intermodal;

secondly, the preservation and development of the capacity and transport capacity of the national railway network, the increase of its interoperability with the panEuropean (for example, on Ukraine's railway transport, equipment and technologies of the third generation are used, and in European countries 4-5 generations, which creates certain technological difficulties when carrying out transit and international transport);

thirdly, the promotion of the social development of the regions covered by the concession, by saving and creating new jobs.

Problem 2. The criterion for the first priority of the transfer of facilities for PPP. The selection of the facilities to be transferred to the PPP should include the following stages: analysis of the level of physical and moral depreciation of individual facilities or sections of the railway network; assessment of the financial needs for their modernization; analysis of the economic and social (positive and negative) consequences of the transfer of a particular facility in the PPP. Such a criterion should be based on an assessment of how its production and economic potential will change, provided that modernization is postponed:

$$
\boldsymbol{C}_{l}=\frac{\boldsymbol{P}_{c}-\boldsymbol{P}_{a}}{\boldsymbol{K I}},
$$

where $P_{c}$ - the potential of the railway infrastructure facility, provided that capital investments in its modernization are carried out this year; $P_{a}-$ the potential of the railway infrastructure facility, provided that capital investments are postponed; $K I$ - the amount of necessary investment.

Then for the transfer to the concession in the first place should be offered facilities for which the greatest reduction in potential will be obtained. This will allow not only carrying out technical and technological renovation of the railway infrastructure but also minimizing possible economic and social losses due to underfunding of its innovative development and maintaining the integrity of the strategic transport network.

\section{Conclusions}

The conducted research has shown that despite significant positive experience and significant advantages of PPP for financing the modernization and development of the railway infrastructure, it is practically not used. This is due to the low investment attractiveness of railway transport due to the high cost of introducing innovations and significant payback periods of investments, and rather strict government regulation of its activities. The SWOT analysis showed that rail transportation not only retains its importance but also has significant growth potential in the conditions of "industrial renaissance" in European countries. At the same time, the complete transfer of the railway infrastructure to private business is not expedient since it is of strategic importance. Therefore, the facilities transferred to the PPP should be both interesting for private business and for the urgent need of modernization, which the state cannot fully finance in the near future. The main criterion determining the possibility of transferring the facility of the railway network to the RRP should be an assessment of the change in its production and economic potential in the event that financing for modernization is delayed. It is determined that in order to maintain the technical and technological integrity of the railway network, in the first place, it is necessary to transfer to PPP the facilities, underfinancing of the modernization of which will lead to a significant reduction in their production and economic potential. At the same time, the problem of forming a set of the indicators remains unresolved, which will most fully reflect the change in both the production-economic and social potential of the railway infrastructure facility in the implementation of modernization, including as a result of PPP.

\section{References:}

Colverson, S., Perera, O. (2011). Sustainable development: is there a role for public-private partnerships? Winnipeg, Manitoba, Canada: International Institute for Sustainable Development.

Cova, P., Pagano, P., Notarpietro, A., Pisani, M. (2017). Secular stagnation, R\&D, public investment and monetary policy: a global-model perspective: working paper. № 1156. Roma: Bank of Italy.

Drexler, T. (2012). Perspektivy razvitiya zheleznykh dorog v Evrope [Prospects for the development of railways in Europe]. EuropeRails. Retrieved from: https://europerails.ru/perspektivy-razvitiya-zheleznyx-dorog-v-evrope/ (accessed 28 June 2018). (in Russian)

Ernest \& Young (CIS) (2014). Course 2030: research infrastructure in Russia. Retrieved from: http://www.ey.com (accessed 28 June 2018). 
European Commission (2017). Investments in EU Transport: Commission proposes $€ 2.7$ billion for 152 projects. Retrieved from: https://ec.europa.eu/transport/themes/infrastructure/news/2017-06-23-2016-cef-call_en (accessed 12 July 2018).

European Commission (2008). Modern rail modern Europe. Retrieved from: https://ec.europa.eu/transport/ sites/transport/files/media/publications/doc/modern_rail_en.pdf (accessed 28 June 2018).

Hanaoka, S., Perez Palapus, H. (2012). Reasonable concession period for build-operate-transfer road projects in the Philippines. International Journal of Project Management, 30(8), 938-949.

International bank for reconstruction and development (2012). Public-Private Partnerships: Reference Guide. Washington.

Kilvington, A. (1996). The BOOT Concept and Other Project Financing Techniques, Lecture Presented for the Study Group in the International Construction Contracts Seminar, 22-26 April 1996, Horsely, UK.

McKinsey Global Institute (2013). Infrastructure productivity: how to save \$1 trillion a year. Retrieved from: https://www.mckinsey.com/ /media/McKinsey/Industries/Capital\%20Projects\%20and\%20Infrastructure/ Our\%20Insights/Infrastructure\%20productivity/MGI\%20Infrastructure_Full\%20report_Jan\%202013.ashx (accessed 18 May 2018).

PwC (2015). Assessing the global transport infrastructure market: Outlook to 2025. Retrieved from: https://www.pwc.com/gx/en/transportation-logistics/pdf/assessing-global-transport-infrastructure-market.pdf (accessed12 July 2018).

Sussman, M. (2013). Realizing railroads' promise (unpublished; Strategic Rail Finance and OnTrackAmerica for AASHTO's Standing Committee on Rail Transportation). Retrieved from: https://www.dot.state.oh.us/ (accessed 23 May 2018).

World Bank Group (2017). Railway PPPs. Retrieved from: https://ppp.worldbank.org/public-private-partnership/ sector/transportation/railway-trains (accessed 28 May 2018).

World Bank Group (2015a). Support to Public-Private Partnerships: Lessons from experience from client countries. International Bank of Reconstruction and Development. Washington.

World Bank Group (2015b). 2015 Transport Sector Global Private Participation in Infrastructure. Retrieved from: http://ppi.worldbank.org/ / media/GIAWB/PPI/Documents/Data-Notes/Transport-Sector-Update-2015 (accessed 03 June 2018).

Varnavsky, V. G. (2005). Partnerstvo gosudarstva i chastnogo sektora: formy, proyekty, riski [Partnership between the state and the private sector: forms, projects, risks]. Moscow: Nauka. (in Russian) 